\title{
Options for managing low grade cervical abnormalities detected at screening: cost effectiveness study
}

\author{
TOMBOLA Group
}

Correspondence to: D K Whynes, School of Economics, University of Nottingham, Nottingham NG7 2RD david.whynes@nottingham.ac.uk

Cite this as: BMJ 2009;339:b2549 doi:10.1136/bmj.b2549

\section{ABSTRACT}

Objective To estimate the cost effectiveness of alternative methods of managing low grade cervical cytological abnormalities detected at routine screening.

Design Cost analysis within multicentre individually randomised controlled trial.

Setting Grampian, Tayside, and Nottingham.

Participants 4201 women with low grade abnormalities. Interventions Cytological surveillance or referral to colposcopy for biopsy and recall if necessary or referral to colposcopy with immediate treatment based on colposcopic appearance.

Main outcome measures Data on resource use collected from participants throughout the duration of the trial (36 months), enabling the estimation of both the direct (health care) and indirect (time and travel) costs of management. Quality of life assessed at recruitment and at $12,18,24$, and 30 months, using the EQ-5D instrument. Economic outcomes expressed as costs per case of cervical intraepithelial neoplasia (grade II or worse) detected, by trial arm, as confirmed at exit, and cost utility ratios (cost per quality adjusted life year (QALY) gained) for the three pairwise comparisons of trial arms.

Results The mean three year discounted costs of surveillance, immediate treatment, and biopsy and recall were $£ 150.20$ ( $€ 177, \$ 249), £ 240.30(€ 283, \$ 415)$, and $£ 241.10$ ( $€ 284, \$ 4000)$, respectively, viewed from the health service perspective. From the social perspective, mean discounted costs were $£ 204.40$ ( $€ 241, \$ 339)$, $£ 339.90$ (€440, \$563), and £327.50 (€386, \$543), respectively. Estimated at the means, the incremental cost effectiveness ratios indicated that immediate treatment was dominated by the other two management methods, although it did offer the lowest cost per case of cervical intraepithelial neoplasia detected and treated. The pronounced skews in the distributions indicated that probabilistic uncertainty analysis would offer more meaningful estimates of cost effectiveness. The observed differences in the cost effectiveness ratios between trial arms were not significant.

Conclusion Judged within the time frame of the TOMBOLA evaluation, there is no compelling economic reason to favour any one follow-up method over either of the others. Trial Registration ISRCTN 34841617.

\section{INTRODUCTION}

By enabling cervical intraepithelial neoplasia to be detected and treated, mass population screening using smear tests has contributed to reducing the incidence of cervical cancer throughout the United Kingdom. ${ }^{12}$ Women with normal test results require no clinical management, other than routine recall for future screening, whereas those with high grade abnormalities should be referred for colposcopy. The optimal management of those with low grade abnormalities detected on screening (borderline nuclear abnormalities or mild dyskaryosis), however, has been the subject of debate..$^{3-6}$ Two alternatives have been advocated-namely, cytological surveillance (further smear tests at regular intervals) or immediate referral for colposcopic examination. When low grade abnormalities are viewed at colposcopy, some clinicians favour a policy of "see and treat," whereby immediate excision, if indicated, is carried out in a single visit. Others prefer a more conservative approach, whereby one or more biopsies are taken at the initial colposcopy, with women returning for treatment at a later date as necessary.

To inform these management debates, a randomised controlled trial (TOMBOLA, trial of management of borderline and other low grade abnormal smears) was established in the late 1990s. The trial is now complete, and full details of its rationale, design, and conduct are available elsewhere. ${ }^{7}$ We report on the economic evaluation conducted in parallel with the clinical trial. The primary function of cervical screening is to identify premalignant lesions and we therefore estimated the expected cost of detecting and treating a case of cervical intraepithelial neoplasia grade II or worse, for each of the three methods under investigation. The use of evaluation results in health policy formulation requires outcomes to be assessed with a common metric, and, in the UK, this metric is the quality adjusted life year (QALY). We present incremental cost effectiveness ratios for pairs of management options in terms of costs per QALY gained.

\section{METHODS}

Resource use

Cervical screening in the UK is provided by the state funded National Health Services (NHS) and is 
available to eligible women free of charge. We collected data on use of resources at the level of individual participants throughout the three year observation period (initial recruitment to exit). To facilitate cost discounting, we recorded the specific timing of every management event relative to the recruitment baseline. The principal resource using events contributing to NHS screening costs were smear tests and colposcopy examinations. The nature of the management methods, however, meant that the colposcopies themselves were often accompanied by additional, contemporaneous interventions-for example, further smear tests, biopsies, large loop excisions of the transformation zone, or cold coagulation. Resource use due to after effects of management during the weeks after the first surveillance smear or the first colposcopy appointment was captured in questionnaires returned by a subsample of trial participants.

In addition to the costs of cervical screening and treatment borne by the NHS, we calculated costs borne by others. Firstly, the opportunity costs of the actual time consumed during consultations and treatments were borne by women privately, their employers, or society as a whole. Secondly, women incurred direct costs of travel to appointments and some needed to finance a substitute carer for their dependants. Thirdly, many women were accompanied to their appointments, resulting in additional opportunity costs and travel expenses for companions. The data on resource use required to estimate the costs of time and travel were obtained from a questionnaire survey of a large subsample $(\mathrm{n}=2269)$ of participants. ${ }^{8}$

\section{Unit costs}

The chosen evaluation baseline was 2004, the year in or around which most of the resource use actually occurred. Accordingly, all unit costs were translated to 2004 prices using the hospital and community health services pay and price index. ${ }^{9}$

As routine smear taking in the UK has always been organised locally in primary care, the NHS cost of testing varies across the countries. Accordingly, we took the unit cost of a smear test to be the average of smear test costs derived from three independent micro-costing studies. Firstly, a specific cost audit was undertaken in Nottingham. This study used data obtained from a survey of resource use among local general practitioners and cost records from the local cytology laboratory. ${ }^{10}$ The second study had collected data at one of the Tayside centres before the start of the trial. ${ }^{11}$ The third had been conducted independently as part of the evaluation of human papillomavirus testing at pilot sites in Bristol, Norwich, and Newcastle. ${ }^{12}$ The three independent estimates of the cost of a smear test were, respectively, £24.30, 26.80 , and $£ 36.90$ at 2004 prices, yielding a mean unit cost of $£ 29.30$ ( $€ 34.5$, $\$ 48.5$ at current conversion rates).

The unit cost of colposcopy was derived from the 2003 NHS reference cost of outpatient colposcopy, based on a national sample of about 250000 events. ${ }^{13}$ The published reference cost included that of the colposcopic examination itself, plus the costs of biopsy, excision, or ablation if carried out. To identify the cost of the procedure alone, we adjusted the published average cost on the basis of the proportion of colposcopies known to have been followed by each of these other procedures in the English programme ${ }^{14}$ and the unit costs of histopathology, ${ }^{13}$ excision, ${ }^{15}$ and ablation. ${ }^{16}$ The unit costs associated with the various procedures related to colposcopy ranged from $£ 111.40$ for an examination only to $£ 210.00$ for a combined examination, smear test, and large loop excision. A small number of smear tests and colposcopies occurred either outside the trial areas or in private practice, although these were all costed as for the corresponding procedures within the trial.

For patients who needed hospital treatment as part of their management, the costs apportioned were specific to both the condition being treated and the type of visit - for example, outpatient, inpatient (the product of the cost per day and length of stay), or accident and emergency. ${ }^{17}$ A hospital outpatient attendance cost $£ 70.40$, inpatient care cost $£ 341.70$ per day, and an emergency admission cost $£ 135.40$. When the costs of condition specific procedures performed were unavailable, we applied day reference costs for gynaecology patients. All additional prescribed medication was costed with British National Formulary (BNF) prices.

The questionnaire study ${ }^{8}$ estimated time and travel costs at $£ 10.10$ per attendance for a smear test and $£ 30.00$ per attendance for colposcopy. Time costs were calculated by combining the reported duration of an event with the prevailing average wage. ${ }^{18}$ Using these estimates, we estimated the costs of time and travel for all formal contacts with care providers for each participant. The estimate for attending a colposcopy appointment without treatment was applied also to investigations in the private sector and to hospital procedures, as a measure of entailed cost. In all cases, we adjusted the time costs applied by the length of visit. Absences from work due to complications and after effects were costed at the prevailing average wage. Reported contacts with specific health services (general practitioner, nurse, NHS or trial help lines) were costed according to the type of service consulted and the mode of contact, either by telephone or in person. ${ }^{9}$ These were apportioned as costs borne by the NHS or the participant, as appropriate.

\section{Outcomes}

Although changes in health state utilities that arise as a result of cervical screening have been modelled, ${ }^{19}$ we collected health state utility data in real time. Participants were invited to complete the EQ-5D ${ }^{20}$ immediately before initial randomisation and at intervals throughout the trial, specifically at $12,18,24$, and 30 months after recruitment. In addition, a subsample of women completed an EQ-5D questionnaire six weeks after their first surveillance smear test or colposcopy appointment. Using the established algorithms for the UK, ${ }^{2122}$ we translated EQ-5D classifications directly into index scores. We were therefore able to 
Table 1|Smear tests and colposcopies by trial arm. Figures are numbers (percentage) of participants

\begin{tabular}{|c|c|c|c|c|c|}
\hline & $\begin{array}{l}\text { Cytological } \\
\text { surveillance }\end{array}$ & $\begin{array}{l}\text { Immediate } \\
\text { treatment }\end{array}$ & $\begin{array}{c}\text { Biopsy } \\
\text { and recall }\end{array}$ & $X^{2}$ & $P$ value \\
\hline \multicolumn{6}{|l|}{ Participants receiving: } \\
\hline \multicolumn{6}{|l|}{ Smear tests: } \\
\hline$\leq 2$ & $451(20.3)$ & $564(57.4)$ & $524(52.4)$ & 662.5 & $<0.001$ \\
\hline $3-4$ & $1302(58.7)$ & $390(39.7)$ & $437(43.7)$ & - & - \\
\hline$>4$ & $466(21.0)$ & $28(2.9)$ & 39 (3.9) & - & - \\
\hline Colposcopies without treatment & $307(13.8)$ & $670(68.2)$ & $994(99.4)$ & 2260.2 & $<0.001$ \\
\hline Colposcopies with treatment & $291(13.1)$ & $498(50.7)$ & $198(19.8)$ & 545.4 & $<0.001$ \\
\hline Both types of colposcopy & $207(9.3)$ & $188(19.1)$ & $193(19.3)$ & 85.2 & $<0.001$ \\
\hline CIN grade II or higher & $269(12.1)$ & $220(22.4)$ & $192(19.2)$ & 61.8 & $<0.001$ \\
\hline \multicolumn{6}{|l|}{ Mean No received/participant: } \\
\hline Smear tests & 3.39 & 2.30 & 2.40 & - & - \\
\hline Colposcopies without treatment & 0.24 & 0.75 & 1.21 & - & - \\
\hline Colposcopies with treatment & 0.13 & 0.55 & 0.21 & - & - \\
\hline
\end{tabular}

plot index scores against time for each participant, with the area under the curve representing the total number of QALYs experienced by the participant between recruitment and 30 months thereafter. By implication, the maximum outcome within the trial for each participant was 2.5 undiscounted QALYs.

We did not expect all women to complete all EQ-5D questionnaires, and many women failed to complete at least one. We excluded from the analysis any woman whose initial or final questionnaire was uncompleted and also any whose questionnaires at two or more adjacent time points were missing. When a single utility value was missing within the individual's EQ-5D sequence, we used linear interpolation between the two known values on either side.

\section{Cost effectiveness}

The accounting conventions for economic evaluation differ between countries. In England, the National Institute for Health and Clinical Excellence (NICE) stipulates an NHS perspective for costs, a validated generic measure of individual health outcomes, and an annual discount rate of $3.5 \%$ for both costs and outcomes. ${ }^{23}$ In most other countries, evaluations adopt a social perspective, whereby costs incurred outside the confines of formal health care are also included. ${ }^{2425}$ Debate continues over the rate at which health outcomes should be discounted, including whether they should be discounted at all. ${ }^{26-28}$ Unlike England, Scotland does not place a priori restraints on accounting conventions. ${ }^{29}$ Given different conventions, we evaluated under different assumptions with respect to perspective and discount rate, and we present two sets of results. For the first, we followed the NICE approach, including only NHS costs and discounting both costs and benefits at 3.5\% a year. For the second, we adopted a social perspective on costs (NHS costs plus costs of time and travel) with costs discounted at 3.5\%, but benefits undiscounted.

In all cases we refer to cervical intraepithelial neoplasia grade II or higher. The mean costs of detection and management for each arm comprised the costs of management of all women in the arm, divided by the number of cases detected at any point during follow-up.

Having ranked the comparators by increasing cost, we estimated the incremental cost effectiveness ratios (the ratios of the mean incremental costs to the mean incremental benefits) for the three pairwise comparisons. In view of the skew typical of trial data (positive skew for costs, negative skew for outcomes), arithmetically calculated means and confidence intervals are generally misleading. We therefore fitted distributions to the individual cost and outcome data for each arm and thereafter used these to estimate the means and distributions of the incremental cost effectiveness ratios. We adopted the standard Monte Carlo approach to uncertainty analysis, ${ }^{30}$ using Palisade @RISK version 4.5 with 10000 iterations for each comparison.

Further details of the data collection and cost effectiveness calculations are provided in the appendix on bmj.com.

\section{RESULTS}

The economic evaluation sample comprised 4201 women, of whom 2219 had been randomised to cytological surveillance, 982 to colposcopy with immediate treatment, and 1000 to colposcopy with biopsy and recall. Table 1 shows the numbers and proportions of women in each of the three trial arms receiving different numbers of smear tests and different types of colposcopies. The category "colposcopies without treatment" includes cases of colposcopic examination only, or examination coupled with further smear tests or with biopsies. For "colposcopies with treatment," the treatment concerned was large loop excision or cold coagulation. Table 1 also shows the women in each arm in whom cervical intraepithelial neoplasia grade II or higher was detected before the exit colposcopies. Differences between the mean numbers of the three different types of procedure by trial arm were significant for all pairwise comparisons, with the 
Table $2 \mid$ Costs and outcomes per woman by trial arm

\begin{tabular}{|c|c|c|c|}
\hline & $\begin{array}{l}\text { Cytological } \\
\text { surveillance }\end{array}$ & $\begin{array}{l}\text { Immediate } \\
\text { treatment }\end{array}$ & $\begin{array}{l}\text { Biopsy } \\
\text { and recall }\end{array}$ \\
\hline \multicolumn{4}{|c|}{ Mean cost (£) by expenditure category: } \\
\hline Smear tests & 101.9 & 68.7 & 71.5 \\
\hline Colposcopy without treatment & 30.7 & 87.7 & 149.5 \\
\hline Colposcopy with treatment & 25.1 & 106.3 & 40.7 \\
\hline Hospital visits & 7.3 & 6.8 & 8.5 \\
\hline Complications & 1.5 & 2.5 & 2.5 \\
\hline Time and travel (non-NHS) & 59.1 & 107.1 & 94.2 \\
\hline \multicolumn{4}{|l|}{ NHS costs $(£):$} \\
\hline Mean & 166.5 & 272.1 & 272.4 \\
\hline Median & 89.5 & 231.4 & 220.7 \\
\hline IQR & $89.5-148.2$ & $172.7-313.5$ & $172.6-319.5$ \\
\hline Mean, discounted & 150.2 & 240.3 & 241.1 \\
\hline Skew coefficient & 2.80 & 3.64 & 2.88 \\
\hline \multicolumn{4}{|l|}{ Social costs $(£)$ : } \\
\hline Mean & 225.6 & 379.1 & 366.6 \\
\hline Median & 130.6 & 343.5 & 305.9 \\
\hline IQR & $130.6-209.4$ & $264.7-428.0$ & 247.7-424.7 \\
\hline Mean, discounted & 204.4 & 339.9 & 327.5 \\
\hline Skew coefficient & 2.62 & 3.37 & 2.77 \\
\hline \multicolumn{4}{|l|}{ Outcomes (QALYs): } \\
\hline Mean & 2.225 & 2.243 & 2.277 \\
\hline Median & 2.348 & 2.348 & 2.383 \\
\hline IQR & $2.120-2.500$ & $2.120-2.500$ & $2.165-2.500$ \\
\hline Mean, discounted & 2.129 & 2.149 & 2.181 \\
\hline Skew coefficient & -2.83 & -2.22 & -2.92 \\
\hline \multicolumn{4}{|c|}{ Mean discounted costs ( $£$ ) per CIN case detected: } \\
\hline NHS perspective & 1241 & 1073 & 1256 \\
\hline Social perspective & 1689 & 1517 & 1706 \\
\hline
\end{tabular}

exception of the mean number of smear tests received by the women in the two colposcopy arms (one way analysis of variance, with Bonferroni correction, at $5 \%$ ). While each woman in the two colposcopy arms underwent at least one colposcopy, most of those randomised to surveillance $(1824,82.2 \%)$ were not subjected to colposcopic investigation.

We had data on after effects from the intervention, such as pain, bleeding, or discharge, from 1646 women (53.9\% from the surveillance arm). In the surveillance arm 1238 women $(55.8 \%)$ reported no after effects with colposcopy compared with $667(33.6 \%)$ in the colposcopy arms $(\mathrm{z}=8.90, \mathrm{P}<0.01)$; and $87(3.9 \%)$ and 412 $(20.8 \%)$ women, respectively, reported taking medication for after effects $(\mathrm{z}=10.51, \mathrm{P}<0.01)$. Within the whole trial sample, 82 women $(2.0 \%)$ made a total of 96 visits to hospital as a result of their management. These visits were a combination of 32 outpatient appointments, 27 day case appointments, 17 inpatient admissions, and 20 emergency visits, which resulted in six further admissions.

Table 2 presents average costs for the major categories of undiscounted costs, plus descriptive statistics of total costs and outcomes, both undiscounted and discounted at 3.5\% a year. Of the three management options, colposcopy with immediate treatment had the lowest cost for detection per case of cervical intraepithelial neoplasia. This result arose because the higher costs per woman in comparison with surveillance and, to a much lesser extent, with biopsy and recall, were more than offset by the increased yield of cervical intraepithelial neoplasia (table 1). The considerable skews of the distributions of cost and outcome indicate the need for uncertainty analysis.

Table 3 presents the uncertainty analysis results for the three pairwise comparisons. For each comparison, the table shows the estimated mean incremental cost effectiveness ratio, plus the likelihood of the nominated management option generating higher costs, higher benefits, or acceptable cost effectiveness in relation to its nominated comparator. An "acceptable incremental cost effectiveness ratio" is a cost per QALY gained of up to and including $£ 30000$ (€65 319, \$49 706), the maximum threshold amount suggested by NICE. ${ }^{31}$

\section{DISCUSSION}

In this study of management of low grade cervical abnormalities our results indicate that different approaches to follow-up had different cost and outcome implications. Of the three approaches, cytological surveillance was the cheapest, colposcopy with biopsy and recall was associated with the most average QALYs per person, and immediate treatment offered the lowest costs per case of cervical intraepithelial neoplasia detected. The size of the confidence intervals for the cost and outcome distributions, however, indicate that none of the three approaches could be shown to be significantly more cost effective than the other two. Thus, our economic evaluation of managing women with low grade abnormalities detected at screening has provided no scientific basis for choosing immediate referral to colposcopy in preference to continued cytological surveillance, or vice versa.

\section{Comparison with other studies}

A recent review observed that immediate treatment after an abnormal smear result has become "accepted internationally." The authors claimed that immediate treatment "decreased patient anxiety" and offered "low costs." 32 Moreover, it has been taken to represent a "safer option" than surveillance in the current medicolegal climate. ${ }^{33}$ Our results suggest that the higher costs of immediate treatment were more than outweighed by its higher yield of neoplasia, making it a lower cost method of detection of cervical intraepithelial neoplasia than cytological surveillance. This finding echoes earlier predictions both from models $^{3435}$ and from a previous empirical study, ${ }^{36}$ although some researchers have found exactly the opposite. ${ }^{37}$

Nevertheless, the cost argument might be less clear cut than has previously been thought. Different studies can have different protocols in terms of, for example, the number of smear tests before referral to colposcopy and the nature and extent of follow-up after colposcopy. Different protocols imply different resource 
Table $3 \mid$ Cost effectiveness by accounting convention

\begin{tabular}{|c|c|c|}
\hline & NICE convention & $\begin{array}{c}\text { Social costs, } \\
\text { undiscounted benefits }\end{array}$ \\
\hline \multicolumn{3}{|c|}{ Immediate treatment $v$ surveillance: } \\
\hline Nominal ICER (£ per QALY) & 4546 & 7378 \\
\hline \multicolumn{3}{|l|}{ Uncertainty analysis: } \\
\hline Higher costs (\%) & 81.0 & 83.7 \\
\hline Higher benefits (\%) & 51.9 & 52.1 \\
\hline Acceptable ICER (\%) & 51.1 & 50.5 \\
\hline $95 \%$ CIs for ICER $(£)$ & -11375 to 11109 & -22977 to 23262 \\
\hline \multicolumn{3}{|c|}{ Biopsy and recall $v$ immediate treatment: } \\
\hline Nominal ICER ( $£$ per QALY) & 26 & -370 \\
\hline \multicolumn{3}{|l|}{ Uncertainty analysis: } \\
\hline Higher costs (\%) & 47.9 & 44.1 \\
\hline Higher benefits (\%) & 53.9 & 56.2 \\
\hline Acceptable ICER (\%) & 53.4 & 55.4 \\
\hline $95 \%$ Cls for ICER (£) & -9390 to 9858 & -18698 to 21344 \\
\hline \multicolumn{3}{|l|}{ Biopsy and recall $v$ surveillance: } \\
\hline Nominal ICER (£ per QALY) & 1764 & 2373 \\
\hline \multicolumn{3}{|l|}{ Uncertainty analysis: } \\
\hline Higher costs (\%) & 80.5 & 80.9 \\
\hline Higher benefits (\%) & 55.1 & 59.1 \\
\hline Acceptable ICER (\%) & 54.3 & 57.4 \\
\hline $95 \%$ Cls for ICER ( $($ ) & -12989 to 11196 & -24651 to 25770 \\
\hline
\end{tabular}

use and, therefore, different costs and different yields. The unit costs of the principal procedures depend on accounting conventions and are likely to vary between settings and between countries. ${ }^{38}$ For example, were the costs of smear tests to be lower relative to those of excision, then the mean cost per case of cervical intraepithelial neoplasia with surveillance would be lower relative to that with referral to colposcopy. In our study, an $£ 80$ increase in the unit cost for colposcopy with treatment would be sufficient to make the cost per case of cervical intraepithelial neoplasia with surveillance cheaper than that with immediate treatment. Interestingly enough, a recent UK study found a higher cost differential. ${ }^{39}$

Measuring outcomes as QALYs allowed us to account for any consequences of management for health state utility in terms of, for example, anxiety, pain, or restrictions in activities over a period of 2 . 5 years. Our results thus contrast with those of earlier studies, which concerned themselves with health impacts judged only within a short time frame of weeks or months at most. ${ }^{40}$

\section{Limitations}

Our results pertain to an economic evaluation within a trial and concern the economics of options for management of follow-up rather than of cancer prevention. Judgments about long term cost effectiveness would require modelling to be undertaken, although such models would require information as yet unavailable. By way of example, the exit colposcopies showed that significantly more cases of cervical intraepithelial neoplasia were reported in the colposcopy arms than in the surveillance arm. On the one hand, it is possible to conclude that a higher level of detection of invasive disease must eventually result from using surveillance rather than colposcopic management. On the other, it is conceivable that many such cases would regress. ${ }^{4142}$ Women who did not might well be identified at future routine screening attendances, entailing neither adverse health consequences from non-detection at present nor any additional costs. In fact, the higher level of cervical intraepithelial neoplasia detected in the colposcopy arms attests to the probability of overdetection and overtreatment, although the extent of this remains unclear. It has been shown that excision might adversely affect future fertility and pregnancy outcomes, ${ }^{434}$ implying the existence of further costs of colposcopic management, as yet unaccounted for.

\section{Policy implications}

As the trial progressed, the UK screening programmes began to replace conventional cytology with liquid based cytology. A modelling exercise ${ }^{45}$ had suggested that liquid based cytology would prove more cost effective than conventional cytology, and implementation was guided by feasibility studies conducted at various sites throughout the UK, including Scottish TOMBOLA centres. A proportion of women in our trial, therefore, would have been screened with liquid based cytology, although their resource use was evaluated as if they had undergone conventional cytology. From the evaluation point of view, it follows that our surveillance arm does not represent current practice in the UK.

How the incremental cost effectiveness ratios of colposcopy relative to liquid based cytology surveillance, as opposed to that with conventional cytology, will differ from those estimated in the present analysis depends on one's interpretation of the current evidence. The unit costs of smear tests are expected to be higher as a result of liquid based cytology. ${ }^{12}$ Trials in France $^{4647}$ and South Africa ${ }^{48}$ have concluded that, despite the additional cost, liquid based cytology could offer test parameters (sensitivity and specificity) inferior to those of conventional cytology. An Italian trial has reported a fall in the positive predictive value of screening as a result of using liquid based cytology. ${ }^{49}$ Meta-analysis of earlier research results has failed to confirm the belief that liquid based cytology was associated with a reduction in the rate of unsatisfactory smear tests, ${ }^{50}$ although recent case studies ${ }^{5152}$ and trials ${ }^{49}$ have reported such a reduction. It therefore remains unclear whether, on balance, liquid based cytology does actually out perform conventional cytology. ${ }^{53}$ With respect to our trial, if the unit cost and the false positive rate of liquid based cytology did prove to be higher than that of conventional cytology, the mean cost of management by surveillance would increase, although the effect might possibly be ameliorated by a reduced need to repeat unsatisfactory smear tests. Clearly, in the event of the surveillance method becoming less efficient, the relative economic advantage of the colposcopy options would increase correspondingly. 


\section{WHAT IS ALREADY KNOWN ON THIS TOPIC}

There has been uncertainty about how best to follow up women with mild or borderline changes in cervical smears

More intensive follow-up by colposcopy might be better for detecting progression to higher grade lesions but might cause more anxiety and side effects and impact on quality of life

\section{WHAT THIS STUDY ADDS}

Taking into account costs, outcomes, and quality of life, follow-up by immediate colposcopy is no more and no less cost effective than follow-up by cytological surveillance

We are grateful for the cooperation and assistance that we received from NHS staff in the coordinating centres and clinical sites. We thank the women who participated in TOMBOLA.

The TOMBOLA Group

Grant holders: Maggie Cruickshank, Graeme Murray, David Parkin, Louise Smart, Eric Walker, Norman Waugh (principal investigator 20047) (University of Aberdeen and NHS Grampian, Aberdeen); Mark Avis, Claire Chilvers, Katherine Fielding, Rob Hammond, David Jenkins, Jane Johnson, Keith Neal, lan Russell, Rashmi Seth, Dave Whynes (University of Nottingham and Nottingham NHS, Nottingham); lan Duncan, Alistair Robertson (University of Dundee and NHS Tayside, Dundee, Tayside) Julian Little (principal investigator 1999-2004) (University of Ottawa, Ottawa, Canada); Linda Sharp (National Cancer Registry, Cork); Ian Russell (Bangor University, Bangor); Leslie Walker (University of Hull, Hull).

Staff in clinical sites and coordinating centres: Breda Anthony, Sarah Bell, Adrienne Bowie, Katrina Brown, Joe Brown, Kheng Chew, Claire Cochran, Seonaidh Cotton, Jeannie Dean, Kate Dunn, Jane Edwards, David Evans, Julie Fenty, Al Finlayson, Marie Gallagher, Nicola Gray, Maureen Heddle, Alison Innes, Debbie Jobson, Mandy Keillor, Jayne MacGregor, Sheona Mackenzie, Amanda Mackie, Gladys McPherson, Ike Okorocha, Morag Reilly, Joan Rodgers, Alison Thornton, Rachel Yeats (Grampian); Lindyanne Alexander, Lindsey Buchanan, Susan Henderson, Tine Iterbeke, Susanneke Lucas, Gillian Manderson, Sheila Nicol, Gael Reid, Carol Robinson, Trish Sandilands (Tayside); Marg Adrian, Ahmed AlSahab, Elaine Bentley, Hazel Brook, Claire Bushby, Rita Cannon, Brenda Cooper, Ruth Dowell, Mark Dunderdale, E Gabrawi, Li Guo, Lisa Heideman, Steve Jones, Salli Lawson, Zoë Philips, Christopher Platt, Shakuntala Prabhakaran, John Rippin, Rose Thompson, Elizabeth Williams, Claire Woolley (Nottingham).

Statistical analysis: Massoud Boroujerdi, Seonaidh Cotton, Kirsten Harrild, John Norrie.

External trial steering committee: Nicholas Day (chair, 1999-2004), Theresa Marteau (chair 2004-), Mahesh Parmar, Julietta Patnick, Ciaran Woodman.

External data monitoring and ethics committee: Doug Altman (chair), Sue Moss, Michael Wells.

Funding: This study was supported by the Medical Research Council (grant No G9700808) and the NHS in England and Scotland. Contributors: Dave Whynes (guarantor), Zoe Philips, Claire Woolley, Seonaidh Cotton, Maggie Cruickshank, Kirsten Harrild, Julian Little, Keith Neal, Linda Sharp, and Norman Waugh carried out these analyses and wrote the paper.

Competing interests: $\mathrm{L}$ has received fees from GlaxoSmithKline as a member of an independent data and safety monitoring committee for a trial of the efficacy of vaccination against HSV.

Ethical approval: This study was approved by the joint research ethics committee of NHS Grampian and the University of Aberdeen, the Tayside committee on medical research ethics, and the Nottingham research ethics committee. All participants provided informed consent.

1 Peto J, Gilham C, Fletcher O, Matthews FE. The cervical cance epidemic that screening has prevented in the UK. Lancet 2004;364:249-56.

2 Comber H, Gavin A. Recent trends in cervical cancer mortality in Britain and Ireland: the case for population-based cervical cance screening. Br / Cancer 2004;91:1902-4.

3 Jones $\mathrm{MH}$. The management dilemma of the mildly abnormal smear: fact or fiction? Ann Acad Med Singapore 1998;27:666-70.

4 Baldauf JJ, Ritter J. Comparison of the risks of cytologic surveillance with atypical cells or low-grade abnormalities on cervical smear: review of the literature. Eur J Obstet Gynecol Reprod Biol 1998;76:193-9.

5 Scheungraber C, Kleekamp N, Schneider A. Management of lowgrade squamous intraepithelial lesions of the uterine cervix. $\mathrm{Br}$ J Cancer 2004;90:975-8.

6 Lindeque BG. Management of cervical premalignant lesions. Best Pract Res Clin Obstet Gynaecol 2005;19:545-61.

7 Cotton SC, Sharp L, Little J, Duncan I, Alexander L, Cruickshank ME, et al. Trial of management of borderline and other low-grade abnormal smears (TOMBOLA): trial design. Contemp Clin Trials 2006;27:449-71.

8 Woolley C, Philips Z, Whynes DK, Cotton SC, Gray NM, Sharp L, et al. United Kingdom cervical cancer screening and the costs of time and travel. Int J Technol Assess Health Care 2007;23:232-9.

9 Curtis L, Netten A, eds. Unit costs of health and social care. Canterbury: Personal Social Services Research Unit, University of Kent, various dates.

10 Sherlaw-Johnson C, Philips Z. An evaluation of liquid-based cytology and human papillomavirus testing within the UK cervical cancer screening programme. Br J Cancer 2004;91:84-91.

11 Waugh N, Smith I, Robertson A, Reed G, Halkerston R, Grant A. Costs and benefits of cervical screening I. The costs of the cervical screening programme. Cytopathology 1996;7:231-40.

12 Legood R, Gray A, Wolstenholme J, Moss S. Lifetime effects, costs, and cost effectiveness of testing for human papillomavirus to manage low grade cytological abnormalities: results of the NHS pilot studies. BMJ 2006;332:79-85.

13 Department of Health. NHS reference costs 2003 2004. London: DH, 2004

14 Information Centre for Health and Social Care. Cervical screening programme, England, 2004-05. London: Government Statistical Service, 2005.

15 Wolstenholme JL, Whynes DK. Stage-specific treatment costs for cervical cancer in the United Kingdom. Eur J Cancer 1998;34:1889-93.

16 Brown RE, Breugelmans JG, Theodoratou D, Bénard S. Costs of detection and treatment of cervical cancer, cervical dysplasia and genital warts in the UK. Curr Med Res Opin 2006;22:663-70.

17 Wolstenholme JL. Counting the costs of cancer care: breast, cervical and lung cancer in Trent [PhD thesis]. University of Nottingham, 2001.

18 National Statistics. Labour market: new earnings survey 2002. Newport: Office for National Statistics, 2002.

19 Insinga RP, Glass AG, Myers ER, Rush BB. Abnormal outcomes following cervical cancer screening: event duration and health utility loss. Med Decis Making 2007;27:414-22.

20 Rabin R, De Charro F. EQ-5D: a measure of health status from the EuroQoL Group. Ann Med 2001;33:337-43.

21 Dolan P, Gudex C, Kind P, Williams A. The time trade-off method: results from a general population study. Health Econ 1996;5:141-54.

22 Dolan P. Modeling valuations for EuroQol health states. Med Care 1997;35:1095-108.

23 National Institute for Health and Clinical Excellence. Guide to the methods of technology appraisal (N1618). London: NICE, 2008.

24 Hjelmgren J, Berggren F, Andersson F. Health economic guidelinessimilarities, differences and some implications. Value Health 2001;4:225-50.

25 Russell LB, Gold MR, Siegel JE, Daniels N, Weinstein MC, for the Panel on Cost-Effectiveness in Health and Medicine. The role of costeffectiveness analysis in health and medicine. JAMA 1996;276:1172-7

26 Bos JM, Postma MJ, Annemans L. Discounting health effects in pharmacoeconomic evaluations: current controversies. Pharmacoeconomics 2005;23:639-49.

27 Brouwer WBF, Niessen LW, Postma MJ, Rutten FFH. Need for differential discounting of costs and health effects in cost effectiveness analyses. BMJ 2005;331:446-8.

28 Gravelle H, Brouwer W, Niessen L, Postma M, Rutten F. Discounting in economic evaluations: stepping forward towards optimal decision rules. Health Econ 2007;16:307-17.

29 Scottish Intercollegiate Guidelines Network. SIGN 50: A guideline developers' handbook. Edinburgh: NHS Quality Improvement Scotland, 2004.

30 Baltussen RMPM, Hutubessy RCW, Evans DB, Murray CJM. Uncertainty in cost-effectiveness analysis. Int J Technol Assess Health Care 2002;18:112-19.

31 National Institute for Health and Clinical Excellence. Social value judgements: principles for the development of NICE guidance. London: NICE, 2005.

32 Cárdenas-Turanzas M, Follen M, Benedet J-L, Cantor SB. See-andtreat strategy for diagnosis and management of cervical squamous intraepithelial lesions. Lancet Oncol 2005;6:43-50.

33 Fairman A, Tan J, Quinn M. Women with low-grade abnormalities on Pap smear should be referred for colposcopy. Aust N ZJ Obstet Gynaecol 2004;44:252-5. 
34 Fung HYM, Cheung LP, Rogers MS, To KF. The treatment of cervical intra-epithelial neoplasia: when could we 'see and loop'. Eur J Obstet Gynecol Reprod Biol 1997;72:199-204.

35 Holschneider $\mathrm{CH}$, Ghosh K, Montz FJ. See-and-treat in the management of high-grade squamous intraepithelial lesions of the cervix: a resource utilisation analysis. Obstet Gynecol 1999;94:377-85.

36 Flannelly G, Campbell MK, Meldrum P, Torgerson DJ, Templeton A, Kitchener HC. Immediate colposcopy or cytological surveillance for women with mild dyskariosis: a cost effectiveness analysis. J Public Health Med 1997;19:419-23.

37 Cecchini S, lossa A, Bonardi R, Ciatto S, Cariaggi P. Comparing two modalities of management of women with cytologic evidence of squamous or glandular atypia: early repeat cytology or colposcopy. Tumori 1997;83:732-4.

38 Helms LJ, Melnikow J. Determining costs of health care services for cost-effectiveness analyses: the case of cervical cancer prevention and treatment. Med Care 1999;37:652-61.

39 Martin-Hirsch P, Rash B, Martin A, Standaert B. Management of women with abnormal cervical cytology: treatment patterns and associated costs in England and Wales. BJOG 2007;114:408-15.

40 Balasubramani L, Orbell S, Hagger M, Brown V, TidyJ. Do women with high-grade cervical intraepithelial neoplasia prefer a see and treat option in colposcopy? BJOG 2007;114:39-45.

41 Holowaty P, Miller AB, Rohan T, To T. Natural history of dysplasia of the uterine cervix. / Natl Cancer Inst 1999;91:252-8.

42 Moscicki A-B, Shiboski S, Hills NK, Powell KJ, Jay N, Hanson EN, et al. Regression of low-grade squamous intra-epithelial lesions in young women. Lancet 2004;364:1678-83.

43 Kyrgiou M, Koliopoulos G, Martin-Hirsch P, Arbyn M, Prendiville W, Paraskevaidis E. Obstetric outcomes after conservative treatment for intraepithelial or early invasive cervical lesions: systematic review and meta-analysis. Lancet 2006;367:489-98.

44 Bruinsma F, Lumley J, Tan J, Quinn M. Precancerous changes in the cervix and risk of subsequent preterm birth. BJOG 2007;114:70-80.
45 Karnon J, Peters J, Platt J, Chilcott J, McGoogan E, Brewer N. Liquidbased cytology in cervical screening: an updated rapid and systematic review and economic analysis. Health Technol Assess 2004;8:1-78.

46 Coste J, Cochand-Priollet B, de Cremoux P, Le Galès C, Cartier I, Molinié V, et al. Cross sectional study of conventional cervical smear, monolayer cytology, and human papillomavirus DNA testing for cervical cancer screening. BMJ 2003;326:733-6.

47 Cochand-Priollet B, Cartier I, de Cremoux P, Le Gales C, Ziol M, Molinie V, et al. Cost-effectiveness of liquid-based cytology with or without hybrid-capture II HPV test compared with conventional Pap smears: a study by the French Society of Clinical Cytology. Diagn Cytopath 2005;33:338-43.

48 Taylor S, Kuhn L, Dupree W, Denny L, De Souza M, Wright Jr TC. Direct comparison of liquid-based and conventional cytology in a South African screening trial. Int J Cancer 2006;118:957-62.

49 Ronco G, Cuzick J, Pierotti P, Cariaggi MP, Palma PD, Naldoni C, et al. Accuracy of liquid based versus conventional cytology: overall results of new technologies for cervical cancer screening randomised controlled trial. BMJ 2007;335:28-31.

50 Davey E, Barratt A, Irwig L, Chan SF, Macaskill P, Mannes P, et al. Effect of study design and quality on unsatisfactory rates, cytology classifications, and accuracy in liquid-based versus conventional cervical cytology: a systematic review. Lancet 2006;367:122-32.

51 Williams ARW. Liquid-based cytology and conventional smears compared over two 12-month periods. Cytopathology 2006;17:82-5

52 Doyle B, O'Farrell C, Mahoney E, Turner L, Magee D, Gibbons D. Liquid-based cytology improves productivity in cervical cytology screening. Cytopathology 2006;17:60-4.

53 Sawaya GF, Sox HC. Trials that matter: liquid-based cervical cytology: disadvantages seem to outweigh advantages. Ann Intern Med 2007;147:668-9.

Accepted: 18 May 2009 